\title{
Reducing Shoulder by Vertical Traction: A One-Man Method for Shoulder Reduction
}

\author{
Hayat Ahmad Khan, ${ }^{1}$ Younis Kamal, ${ }^{1}$ Mohammad Ashraf Khan, ${ }^{1}$ Munir Farooq, \\ Naseemul Gani, ${ }^{1}$ Nazia Hassan, ${ }^{2}$ Adil Bashir Shah, ${ }^{1}$ and Mohammad Shahid Bhat ${ }^{1}$ \\ ${ }^{1}$ Department of Orthopaedics, B \& J Hospital, GMC Srinagar, Kashmir 190005, India \\ ${ }^{2}$ GMC Srinagar, Kashmir, India
}

Correspondence should be addressed to Hayat Ahmad Khan; drhayatkhan@gmail.com

Received 31 July 2015; Revised 18 February 2016; Accepted 20 March 2016

Academic Editor: Shyu-Jye Wang

Copyright (c) 2016 Hayat Ahmad Khan et al. This is an open access article distributed under the Creative Commons Attribution License, which permits unrestricted use, distribution, and reproduction in any medium, provided the original work is properly cited.

\begin{abstract}
Fifty percent of joint dislocations reported to the emergency department are of shoulder joint. Various techniques are used to reduce the shoulder and Spaso technique is the least known to the orthopaedic residents which is a simple one-man vertical traction method of shoulder reduction. We evaluated the effectiveness of vertical traction method for anterior shoulder dislocation by orthopaedic residents. Sixty consecutive patients of anterior glenohumeral dislocation attending the emergency department of our hospital were taken up for the study. The reduction was done using Spaso technique. Right shoulder was dislocated in 40 patients and 31 patients had recurrent shoulder dislocation. In 55 patients, shoulder was reduced without the use of any anaesthesia. In patients where no anaesthesia was used, the time of traction ranged from 45 seconds to 5 minutes, while under anaesthesia the time of traction ranged from 1 to 4 minutes. Twenty-one patients had associated greater tuberosity fracture which did not affect the method of reduction and all of them were reducible. No complication was reported, and all the patients were satisfied with the method. In conclusion vertical traction method is a good technique for reducing anterior shoulder dislocation with an easy learning curve among the residents and no complication has been reported so far.
\end{abstract}

\section{Introduction}

Of all the joint dislocations encountered in the accident and emergency departments, shoulder joint takes half of the share [1]. Krøner et al. (1989) reported the annual incidence of 17 per 100000 [2]. More and more people now indulge in recreational and sports activity which may be the cause for increased incidence of glenohumeral dislocation. Majority of shoulders are dislocated anteriorly (90-98\%) with trauma being the main cause $[3,4]$. Whatever the cause is, the joint needs to be reduced ideally. The method has to be quick, effective, and least painful to the patient without causing any iatrogenic injury. Many reduction techniques for shoulder joint have been documented with each having its advantages and disadvantage [5-7]. The relatively new technique of anterior shoulder joint reduction is the Spaso technique which is the one-man vertical traction method of reduction [8]. We conducted a prospective study to report our experience of using this technique to reduce shoulder. This is first study being conducted in India or even Asia to the best of our knowledge. It is also first of its kind given that only orthopaedic residents are involved in the study.

\section{Aims and Objectives}

Aim of this study was to evaluate the effectiveness of vertical traction method for anterior shoulder dislocation by orthopaedic residents.

\section{Material and Methods}

Sixty consecutive patients of anterior glenohumeral dislocation attending the Emergency Department of Bone and Joint Hospital were taken up for the study after the clinical and radiological diagnosis was made. The reduction was attempted by one of the authors. Demographic data including 


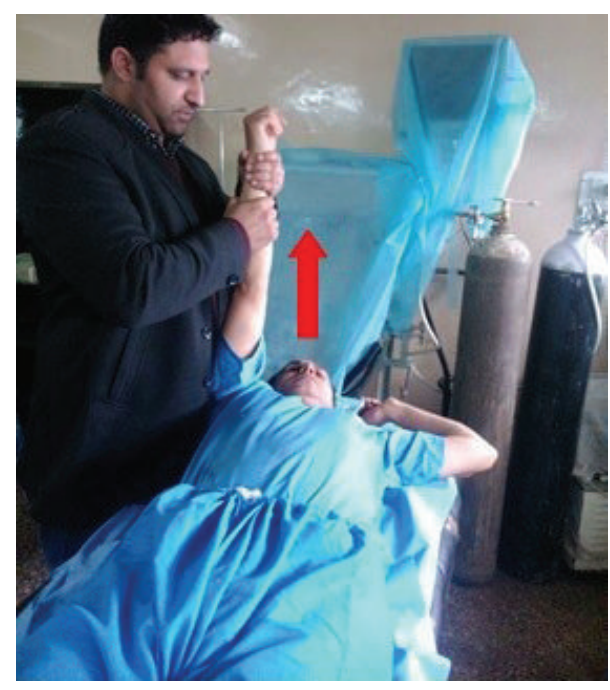

(a)



(b)



(c)

FIGURE 1: Method of shoulder reduction. Figure showing the method of shoulder reduction. (a) Vertical traction, (b) external rotation, and (c) palpation of humeral head being done. Red arrow shows the direction of force.

age, site, associated fracture of greater tuberosity, history of previous dislocation, any joint laxity, and number of manipulation attempts were noted on the patients case sheet. Mode of trauma and time since dislocation were noted. All patients gave consent for the procedure and the study was performed in accordance with the ethical standards and was approved by ethical committee. himself.

The technique used was similar to that used by Spaso

3.1. Technique. Patients were asked to lie down supine on the bed. Procedure was explained to the patients so that apprehension was over. Since the original article has not mentioned about the anaesthesia used, we followed up all cases without anaesthesia and reserved anaesthesia for patients where it was necessary. As advised by Spaso the affected limb was held at wrist and slowly elevated (forward flexion) and vertical traction was applied. While maintaining vertical traction, the shoulder was slightly externally rotated. A clunk was heard or felt when reduction was done (Figures 1, 2, and 3).

The patient tends to lift up the shoulder off the bed or stop the surgeon with opposite hand in case of discomfort. We stopped the further movement of the limb while maintaining the traction. Most of the times pain subsided allowing further traction. If reduction did not come, the head was palpated with the other hand and gently pushed. If still reduction was unsuccessful, anaesthesia was given and above procedure is repeated under anaesthesia.

After reduction, shoulder immobiliser was applied and patients were followed up in outpatient department.

\subsection{Review of Other Reduction Methods}

3.2.1. Hippocrates Method. With the patient lying supine, the physician's foot is placed in the patient's axilla against the chest wall while leaning backward. The affected arm is 

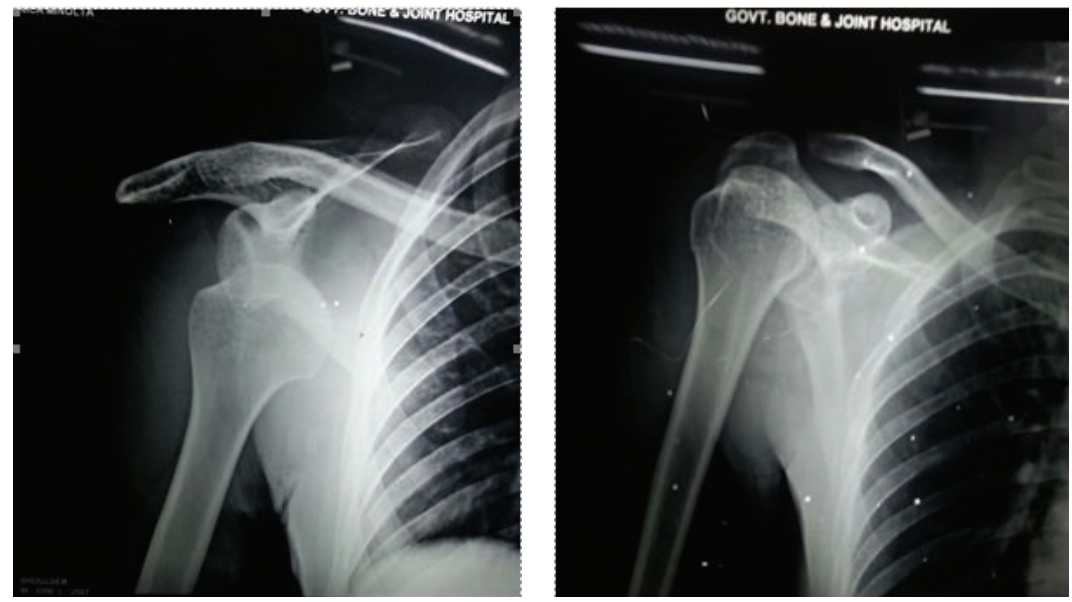

FIGURE 2: X-rays showing dislocated and reduced shoulder joint.
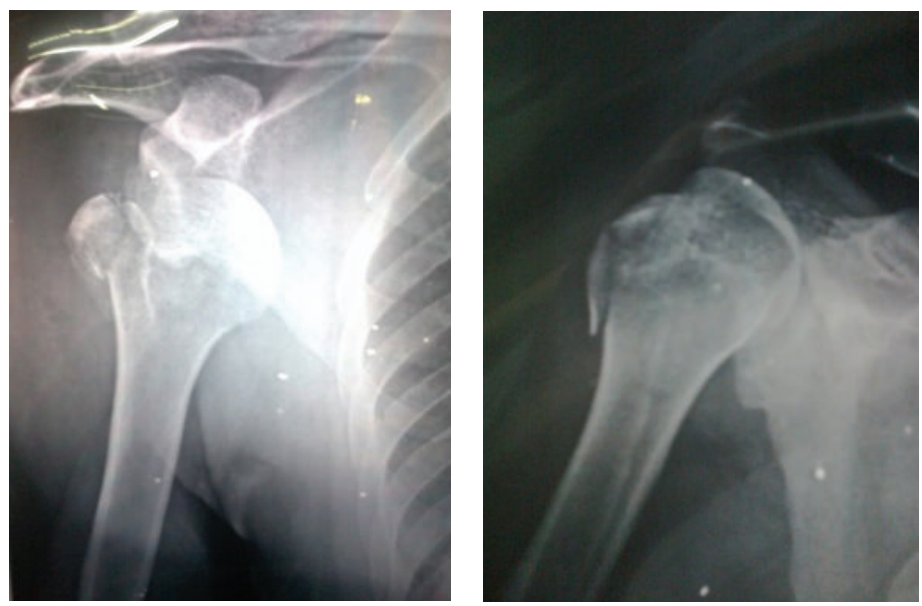

FIGURE 3: X-rays showing dislocated and reduced shoulder with fractured greater tuberosity.

abducted and gentle traction is applied steadily for about a minute. The foot acts as a counterforce and as a lever to push the humeral head laterally while the physician pulls the head toward the patient's foot along the surface of the glenoid.

3.2.2. Milch Technique. The patient lies supine or head elevated $30^{\circ}$. The physician stands on the affected side and places the ipsilateral hand upon the patients shoulder so that the fingers support the top of the shoulder, while the thumb is applied to the under surface of the dislocated humeral head to hold it in place. The elbow of the affected arm is put into $90^{\circ}$ flexion. The physician gently abducts the arm into the overhead position with opposite hand and externally rotates it. The humeral head in the axilla is then pushed over the glenoid rim with direct pressure of the thumb.

Axial traction may be applied with countertraction via the hand or a foot upon the top of the shoulder (this was not in Milch's original description).

3.2.3. Kocher. It uses external rotation to roll the humeral head over the anterior glenoid rim. In this method the arm is flexed at elbow and pressed against the body. It is then rotated outwards till resistance is felt. The upper arm is then lifted in sagittal plane and turned inwards. Kocher did not use traction in his original description.

3.2.4. External Rotation Method. In this method the patient can be supine, sitting, or $45^{\circ}$ recumbent. The affected arm is adducted against the torso. The elbow is flexed to $90^{\circ}$. The upper arm is externally rotated slowly and gently, using the forearm as a lever by grasping the wrist with one hand and the elbow with the other hand.

3.2.5. Scapular Manipulation Methods. In this method the patient is kept prone. The shoulder is kept in $90^{\circ}$ of forward flexion and external rotation. The forearm is suspended from the stretcher with the wrist secured and the elbow flexed. Forward traction is maintained with about $5-7 \mathrm{Kg}$ of hanging weight to the wrist or with manual traction for 510 minutes. With the patient relaxed, the physician pushes medially on the tip of the scapula with both thumbs and 
TABLE 1

\begin{tabular}{|c|c|c|}
\hline $\begin{array}{l}\text { Number of patients } \\
\text { Total } 60\end{array}$ & $\begin{array}{c}\text { Male } \\
N=38(63.3 \%)\end{array}$ & $\begin{array}{c}\text { Females } \\
N=22(36.7 \%)\end{array}$ \\
\hline Side & Right $n=40(64 \%)$ & Left $n=20(33 \%)$ \\
\hline Age & $\begin{array}{c}\text { Range [20 years to } 75 \\
\text { years] }\end{array}$ & \\
\hline $\begin{array}{l}\text { Success rate } \\
100 \%\end{array}$ & $\begin{array}{l}\quad N=55(91.67 \%) \\
\text { Without anaesthesia }\end{array}$ & $\begin{array}{c}N=5(8.33 \%) \\
\text { Under anaesthesia }\end{array}$ \\
\hline
\end{tabular}

lifts it occasionally while externally rotating the superior and medial aspects of the scapula.

\section{Results}

Among the cohort of 60, we had 38 males and 22 females. Right shoulder was dislocated in 40. And 31 patients had recurrent shoulder dislocation. Age group was between 20 and 75 . Time of reporting to hospital ranged from $30 \mathrm{~min}$ to 2 weeks.

In 55 patients, shoulder was reduced without the use of any anaesthesia. Among the cases, ten were referred from the peripheral health centres and few attempts to reduce the shoulder were already made. Five patients were first tried without anaesthesia but the shoulder could not be reduced. Under anaesthesia all the shoulders were reduced by the same technique.

In patients where no anaesthesia was used, the time of traction ranged from 45 seconds to 5 minutes while under anaesthesia the time of traction ranged from 1 minute to 4 minutes. Twenty-one patients had associated greater tuberosity fracture and only two needed fixation.

Thirty-one patients had recurrent dislocation. Twentyeight shoulders were previously reduced by other methods and all of them regarded this technique as better than the previous one. The demography of the patients is given in Table 1.

Table 2 summarizes the various techniques given by various authors and the percentage in which the premedication was used. Studies with more than 50 cases have been included. Also the authors in all the studies are male authors as in our case; we presume the female doctors who work in emergency centres can learn the technique as this has an easy learning curve.

\section{Discussion}

The method of reducing the shoulder joint is as old as the history of medical science. Different methods are given in the literature and most of the orthopaedicians have the opinion that one should use a method of reduction with which he is well versed. The review done by Ashton and Hassan [20] suggested that the individual preference for the method of reduction is not supported by evidence. In 2006 Kuhn presented the study showing that little data exists to predict best method of reduction or the type of anaesthesia [21].

Various methods used for shoulder reduction are still being practiced and various operators give good results. Traditional traction countertraction, Kocher's, Stimson's, scapular manipulation and Milch maneuver [10, 16, 22-24]. The number of methods available itself signifies that none of them is an ideal method and different methods need to be compared under a randomised control to know the effectiveness.

The complications associated with traction countertraction methods include axillary nerve injury, fractures of humeral head or shaft, and even capsular damage.

Also the countertraction causes muscle spasm which makes reduction more difficult or even impossible and may be the cause for need of general anaesthesia. In vertical traction method, all the forces are acting in the same direction and there is no force of opposition. The Spaso technique relies on sound biomechanical principles in that in the overhead position, all of the shoulder muscles course directly upwards inserting into the humerus thereby assisting reduction to the anatomical position $[8,11]$. This contrasts with the methods performed with the arm at the side, where each of the shoulder muscles is running in a different direction usually requiring the use of more force or more sedation and hence the risk of fracture is increased.

Spaso method is the least known method among the techniques. The reason may be that the original study was published in the nonindexed journal and most of the orthopaedicians had no access to that. However Yuen et al. [25] have promoted the technique and published paper using the same technique. They further emphasised that further studies need to be conducted for knowing the effectiveness of technique. We took the initiative because this technique needed only single operator and no such study has been conducted at an orthopaedic centre which is overburdened by the road traffic accidents, infective cases, and multiple trauma patients.

We see almost 100 to 120 shoulder dislocation patients per year besides other orthopaedic trauma. Being a tertiary care institute and catering for a population of five millions, it is always a busy trauma centre. Also the analgesics like pethidine and morphine are not available for the masses in the developing countries like ours. This study was different from that conducted by Yuen et al. as no pethidine, valium, or morphine was used.

We were able to reduce all our patients with this technique although five patients needed anaesthesia. Presence of greater tuberosity fracture did not affect the method of reduction and all of them were reducible. Two patients were operated on for fixation of greater tuberosity. Of the five patients who needed anaesthesia, all had dislocations for the first time and two had greater tuberosity fracture.

No complication was reported in any of the patients and all patients were satisfied with the method. Few patients complained of pain after procedure which subsided after few hours. No patient had severe pain during or after the procedure.

\section{Conclusion}

Vertical traction method is a good technique for reducing anterior shoulder dislocation with an easy learning curve 
TABLE 2: Table showing various studies conducted so far by various authors using different techniques. Only studies having fifty $(n \geq 50)$ or more cases have been included.

\begin{tabular}{|c|c|c|c|c|c|c|c|}
\hline Study type & Reduction method & Year & Author & No. of patients & $\begin{array}{l}\text { Success } \\
\text { rate }\end{array}$ & Complications & $\begin{array}{c}\text { Without } \\
\text { premedication }\end{array}$ \\
\hline Case series & $\begin{array}{l}\text { Snow bird looped } \\
\text { technique }\end{array}$ & 1995 & Westin et al. [4] & 118 & $114(97 \%)$ & $0 \%$ & $93 \%$ \\
\hline Case series & Autoreduction & 1997 & Ceroni et al. [9] & 100 & $60(60 \%)$ & $0 \%$ & $70 \%$ \\
\hline Case series & Milch & 1981 & Russell et al. [10] & 76 & $68(89 \%)$ & $0 \%$ & $69 \%$ \\
\hline Case series & Milch & 1982 & $\begin{array}{c}\text { Janecki and Shahcheragh } \\
{[6]}\end{array}$ & 50 & $50(100 \%)$ & $0 \%$ & $34 \%$ \\
\hline RCT & Milch & 1986 & Beattie et al. [11] & 56 & $39(70 \%)$ & $0 \%$ & NA \\
\hline Case series & Milch & 1992 & Johnson et al. [12] & 142 & $122(86 \%)$ & $0 \%$ & $73 \%$ \\
\hline Case series & Modified Milch & 1989 & Canales Cortés et al. [13] & 128 & $107(84 \%)$ & NA & $33 \%$ \\
\hline Case series & Modified Milch & 1992 & Garnavos [14] & 75 & $71(95 \%)$ & $0 \%$ & $100 \%$ \\
\hline RCT & Kocher & 1986 & Beattie et al. [11] & 55 & $40(73 \%)$ & $2 \%$ & NA \\
\hline Case series & External rotation & 1977 & Leidelmeyer [15] & 50 & $50(100 \%)$ & $0 \%$ & $0 \%$ \\
\hline Case series & External rotation & 1979 & Mirick et al. [16] & 85 & $68(80 \%)$ & $0 \%$ & NA \\
\hline Case series & External rotation & 1986 & Danzl et al. [17] & 100 & $78(78 \%)$ & $1 \%$ & $0 \%$ \\
\hline Case series & $\begin{array}{c}\text { Scapular } \\
\text { manipulation }\end{array}$ & 1982 & Anderson et al. [18] & 51 & $47(92)$ & $0 \%$ & $34 \%$ \\
\hline Case series & $\begin{array}{c}\text { Scapular } \\
\text { manipulation-seated }\end{array}$ & 1993 & McNamara [19] & 61 & $48(79 \%)$ & $0 \%$ & $64 \%$ \\
\hline Present study & Spaso technique & 2013-2014 & Khan et al. & 60 & $100 \%$ & $0 \%$ & $91.67 \%$ \\
\hline
\end{tabular}

among the residents and no complication has been reported so far.

\section{Competing Interests}

The authors declare that they have no competing interests.

\section{Authors' Contributions}

All authors contributed equally to this work.

\section{Acknowledgments}

The authors thank M. C. Yuen for providing them with the necessary material and help whenever required.

\section{References}

[1] R. Blake and J. Hoffman, "Emergency department evaluation and treatment of the shoulder and humerus," Emergency Medicine Clinics of North America, vol. 17, no. 4, pp. 859-876, 1999.

[2] K. Krøner, T. Lind, and J. Jensen, "The epidemiology of shoulder dislocations," Archives of Orthopaedic and Trauma Surgery, vol. 108, no. 5, pp. 288-290, 1989.

[3] J. A. Hill, "Epidemiologic perspective on shoulder injuries," Clinics in Sports Medicine, vol. 2, no. 2, pp. 241-247, 1993.

[4] C. D. Westin, E. A. Gill, M. E. Noyes, and M. Hubbard, "Anterior shoulder dislocation: a simple and rapid method for reduction," American Journal of Sports Medicine, vol. 23, no. 3, pp. 369-371, 1995.

[5] K. K. Eachempati, A. Dua, R. Malhotra, S. Bhan, and J. R. Bera, "The external rotation method for reduction of acute anterior dislocations and fracture-dislocations of the shoulder," Journal of Bone and Joint Surgery A, vol. 86, no. 11, pp. 2431-2434, 2004.

[6] C. J. Janecki and G. H. Shahcheragh, "The forward elevation maneuver for reduction of anterior dislocations of the shoulder," Clinical Orthopaedics and Related Research, vol. 164, pp. 177-180, 1982.

[7] H. R. Manes, "A new method of shoulder reduction in the elderly," Clinical Orthopaedics and Related Research, vol. 147, pp. 200-202, 1980.

[8] S. Miljesic and A.-M. Kelly, "Reduction of anterior dislocation of the shoulder: the Spaso technique," Emergency Medicine, vol. 10, no. 2, pp. 173-175, 1998.

[9] D. Ceroni, H. Sadri, and A. Leuenberger, "Anteroinferior shoulder dislocation: an auto-reduction method without analgesia," Journal of Orthopaedic Trauma, vol. 11, no. 6, pp. 399-404, 1997.

[10] J. A. Russell, E. M. Holmes III, D. J. Keller, and J. H. Vargas III, "Reduction of acute anterior shoulder dislocations using the milch technique: a study of ski injuries," Journal of Trauma: Injury, Infection and Critical Care, vol. 21, no. 9, pp. 802-804, 1981.

[11] T. F. Beattie, D. J. Steedman, A. McGowan, and C. E. Robertson, "A comparison of the Milch and Kocher techniques for acute anterior dislocation of the shoulder," Injury, vol. 17, no. 5, pp. 349-352, 1986.

[12] G. Johnson, W. Hulse, and A. McGowan, "The Milch Technique for reduction of anterior shoulder dislocations in an accident and emergency department," Archives of Emergency Medicine, vol. 9, no. 1, pp. 40-43, 1992.

[13] V. Canales Cortés, L. García-Dihinx Checa, and J. Rodriguez Vela, "Reduction of acute anterior dislocations of the shoulder without anaesthesia in the position of maximum muscular relaxation," International Orthopaedics, vol. 13, no. 4, pp. 259262, 1989. 
[14] C. Garnavos, “Technical note: modifications and improvements of the milch technique for the reduction of anterior dislocation of the shoulder without premedication," Journal of Trauma, vol. 32, no. 6, pp. 801-803, 1992.

[15] R. Leidelmeyer, "Reduced! A shoulder, subtly and painlessly," The Journal of Emergency Medicine, vol. 9, pp. 223-234, 1977.

[16] M. J. Mirick, J. E. Clinton, and E. Ruiz, "External rotation method of shoulder dislocation reduction," Journal of the American College of Emergency Physicians, vol. 8, no. 12, pp. 528-531, 1979.

[17] D. F. Danzl, S. J. Vicario, G. L. Gleis, J. R. Yates, and D. L. Parks, "Closed reduction of anterior subcoracoid shoulder dislocation. Evaluation of an external rotation method," Orthopaedic Review, vol. 15, no. 5, pp. 311-315, 1986.

[18] D. Anderson, R. Zvirbulis, and J. Ciullo, "Scapular manipulation for reduction of anterior shoulder dislocations," Clinical Orthopaedics and Related Research, vol. 164, pp. 181-183, 1982.

[19] R. M. McNamara, "Reduction of anterior shoulder dislocations by scapular manipulation," Annals of Emergency Medicine, vol. 22, no. 7, pp. 1140-1144, 1993.

[20] H. R. Ashton and Z. Hassan, "Best evidence topic report. Kocher's or Milch's technique for reduction of anterior shoulder dislocations," Emergency Medicine Journal, vol. 23, no. 7, pp. 570-571, 2006.

[21] J. E. Kuhn, “Treating the initial anterior shoulder dislocationan evidence-based medicine approach," Sports Medicine and Arthroscopy Review, vol. 14, no. 4, pp. 192-198, 2006.

[22] H. Milch, "Treatment of dislocation of the shoulder," Surgery, vol. 3, pp. 732-738, 1938.

[23] L. A. Stimson, "An easy method of reducing dislocations of the shoulder and hip," Med Record, vol. 57, pp. 356-357, 1900.

[24] M. Daya, "Shoulder," in Rosen's Emergency Medicine. Concepts and Clinical Practice, J. A. Marx, R. S. Hockberger, and R. M. Walls, Eds., pp. 576-606, Mosby, St. Louis, Mo, USA, 5th edition, 2002.

[25] M.-C. Yuen, P.-G. Yap, Y.-T. Chan, and W.-K. Tung, "An easy method to reduce anterior shoulder dislocation: the Spaso technique," Emergency Medicine Journal, vol. 18, no. 5, pp. 370$372,2001$. 


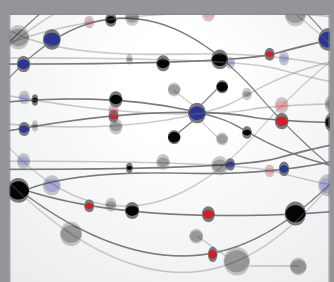

The Scientific World Journal


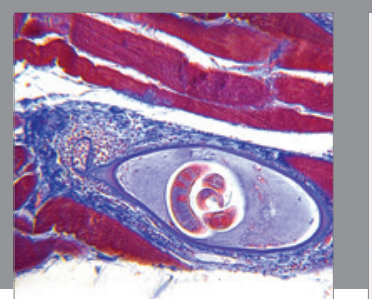

Gastroenterology Research and Practice

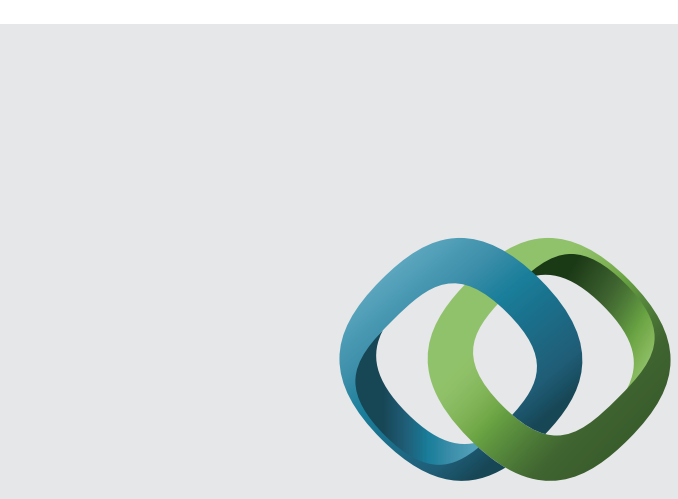

\section{Hindawi}

Submit your manuscripts at

http://www.hindawi.com
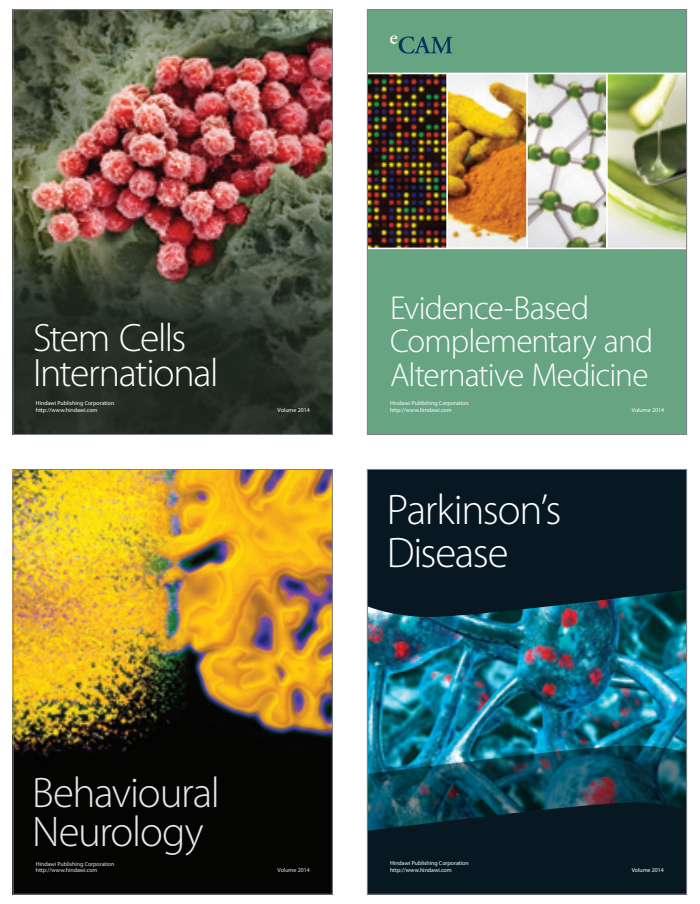
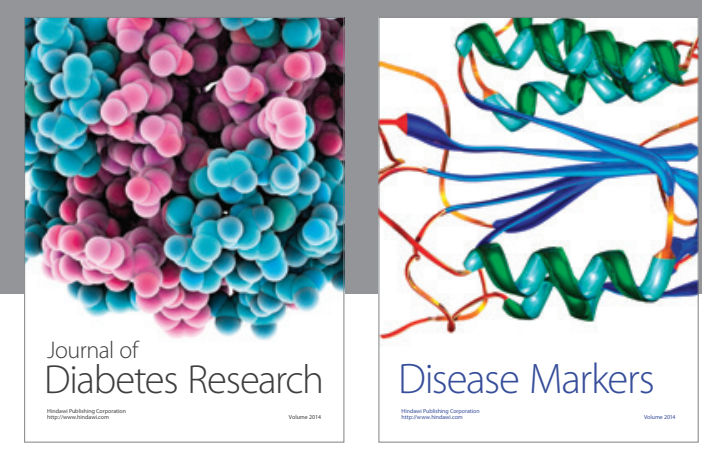

Disease Markers
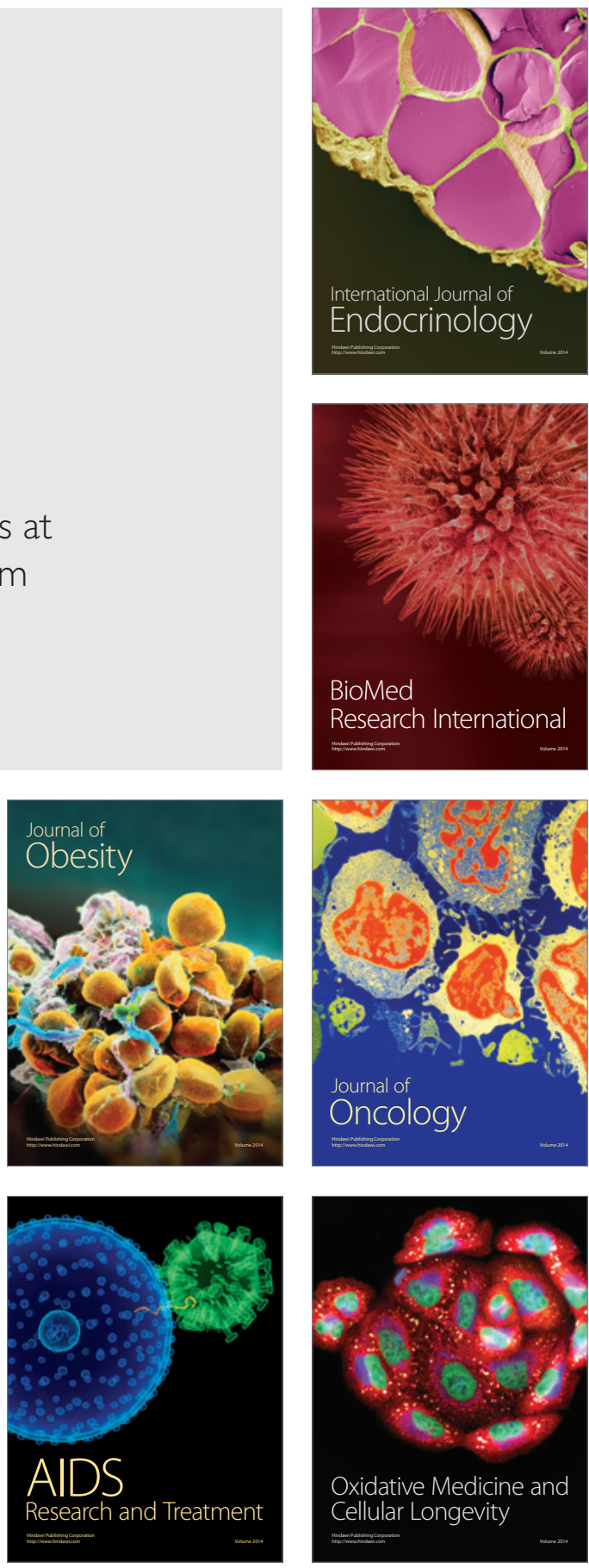